\title{
Repeated Automated Mobile Text Messaging Reminders for Follow-Up of Positive Fecal Occult Blood Tests: Randomized Controlled Trial
}

Revital Azulay ${ }^{1,2^{*}}$, MSc, PhD; Liora Valinsky ${ }^{3 *}, \mathrm{RN}, \mathrm{MPH} ;$ Fabienne Hershkowitz ${ }^{3 *}, \mathrm{PhD}$; Racheli Magnezi ${ }^{{ }^{*}}$, MHA, $^{2}$ $\mathrm{PhD}$

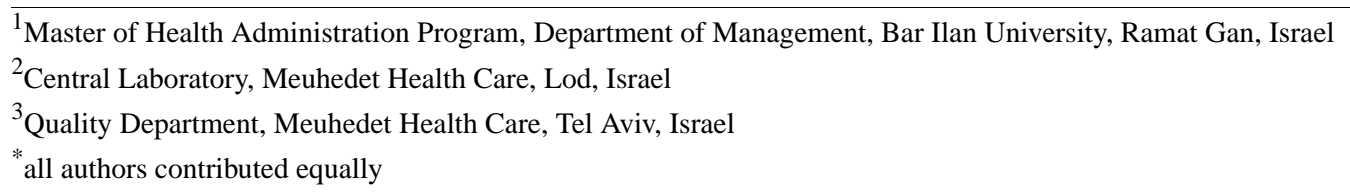

Corresponding Author:

Revital Azulay, MSc, PhD

Central Laboratory

Meuhedet Health Care

Pesach Lev 5

Lod,

Israel

Phone: 97297289130421

Fax: 97297289130422

Email: eazulay39@gmail.com

\section{Abstract}

Background: Fecal occult blood tests (FOBTs) are recommended by the US Preventive Services Task Force as a screening method for colorectal cancer (CRC), but they are only effective if positive results are followed by colonoscopy. Surprisingly, a large proportion of patients with a positive result do not follow this recommendation.

Objective: The objective of this study was to examine the effectiveness of text messaging (short message service, SMS) in increasing adherence to colonoscopy follow-up after a positive FOBT result.

Methods: This randomized controlled trial was conducted with patients who had positive CRC screening results. Randomization was stratified by residential district and socioeconomic status (SES). Subjects in the control group $(n=238)$ received routine care that included an alert to the physician regarding the positive FOBT result. The intervention group $(n=232)$ received routine care and 3 text messaging SMS reminders to visit their primary care physician. Adherence to colonoscopy was measured 120 days from the positive result. All patient information, including test results and colonoscopy completion, were obtained from their electronic medical records. Physicians of study patients completed an attitude survey regarding FOBT as a screening test for CRC. Intervention and control group variables (dependent and independent) were compared using chi-square test. Logistic regression was used to calculate odds ratios (ORs) and 95\% CIs for performing colonoscopy within 120 days for the intervention group compared with the control group while adjusting for potential confounders including age, gender, SES, district, ethnicity, and physicians' attitude.

Results: Overall, 163 of the 232 patients in the intervention group and 112 of the 238 patients in the control group underwent colonoscopy within 120 days of the positive FOBT results (70.3\% vs 47.1\%; OR 2.17, 95\% CI 1.49-3.17; P<.001); this association remained significant after adjusting for potential confounders $(P=.001)$.

Conclusions: A text message (SMS) reminder is an effective, simple, and inexpensive method for improving adherence among patients with positive colorectal screening results. This type of intervention could also be evaluated for other types of screening tests.

Trial Registration: ClinicalTrials.gov NCT03642652; https://clinicaltrials.gov/ct2/show/NCT03642652 (Archived by WebCite at http://www.webcitation.org/74TIICijl)

(JMIR Mhealth Uhealth 2019;7(2):e11114) doi: 10.2196/11114 


\section{KEYWORDS}

adherence; cancer screening; colonoscopy; fetal occult blood test; patient-physician relationship; positive colorectal cancer screening; SMS; text reminder

\section{Introduction}

Colorectal cancer (CRC) is a major cause of morbidity and mortality throughout the world. It is the second most common malignant disease [1,2], with $90 \%$ survival when it is identified early and immediate surgical intervention is performed. In Israel, the screening policy for average-risk individuals aged 50-75 years is an annual fecal occult blood test (FOBT) [3]. A patient with positive FOBT result requires immediate follow-up with colonoscopy, and surgery should be performed when CRC is detected. A delay in follow-up markedly undermines the benefits of CRC screening, including incidence, mortality, life-years saved, and net costs of screening [4-7]. Recommendations regarding the time between a positive result and colonoscopy vary across countries, ranging between 30 and 180 days [8-13]. In Israel, the Ministry of Health guidelines define the standard period between a positive FOBT result and a follow-up colonoscopy as 90 days $[3,14]$. From the literature, we learned that $40 \%-60 \%$ of individuals who undergo FOBT screening do not continue with follow-up after a positive result $[7,15,16]$. In the Israeli population, follow-up rates after a positive FOBT result are $71 \%$, and the proportion of patients who complete follow-up varies across health care organizations, with the proportion in Meuhedet being about $50 \%$. The median time to follow-up, nationally, is 112 days, which is significantly longer than the recommended 90 days [17].

Barriers to follow-up after a positive FOBT result have been identified in the literature [18-23] and are divided into 4 general groups based on whether they are related to patients, physicians, providers, or information technology [24-26]. Intervention programs have been developed to target each of these groups [27]. Patient-targeted interventions include educational strategies, peer counselors or navigators, reminders, and coupons. The interventions were effective for short-term, but not long-term, follow-up. Several studies have described interventions aimed at increasing follow-up rates and have showed mixed results [13,20,28-41]. When the patient-physician relation is good and based on clear communication and trust, the patient is more likely to adhere to and fulfill the physician's instructions $[42,43]$.

Studies addressing patient interventions have used letters, emails, telephone calls, and nurse navigators. Mailed invitations were found to be as effective as telephone reminders and increased follow-up rates by approximately $30 \%$ in an Italian study [40]. In a Scottish study, a reminder phone call that included making an appointment for colonoscopy increased adherence by $4.7 \%$ [13]. In a British study aimed at minority populations, the study nurse called patients repeatedly, invited them to the clinic, and scheduled a colonoscopy appointment for each one; this intervention increased follow-up by $8.4 \%$ [39]. All these interventions were found to be effective, but some are extremely labor-intensive and time-consuming.
To date, few studies have examined the effectiveness of short message service (SMS) text messaging as an intervention tool within community medical settings. SMS text message reminders have been shown to be effective in improving preparation for colonoscopy in Korea [44]; they increased Streptococcus pneumonia immunization in a primary care setting in Lebanon [45] by $7.2 \%$ (less than phone calls, but more than emails). A literature review examining the effect of SMS text messages and emails to improve diabetes management showed that simple phone calls, letters, or SMS text message reminders can have a positive impact on clinical and behavioral outcomes [46]. A systematic review [47] indicated that SMS text messaging interventions improved patients' medication adherence rate. In a review of the factors associated with nonadherence to oral antiplatelet therapy in acute coronary syndrome and interventions that modify these factors, only reminder-based interventions, including SMS text messages, had consistently beneficial impacts on adherence outcomes at 3 and 12 months [48]. In a randomized controlled trial designed to assess the effects of SMS text message reminders on adherence to a healthy diet, medication, and smoking cessation among adult patients with cardiovascular disease, researchers found that SMS text messaging was effective in improving adherence to a healthy diet and medication but not smoking cessation [49]. A different study reported increased success for smoking cessation among patients attending control visits as a result of scheduled clinic appointments following SMS text message reminders. The smoking cessation rate was $24 \%$ in patients who did not respond to SMS text message reminders at all and $28.6 \%(\mathrm{n}=28)$ in patients answering any SMS text message at least once $(P=.001)$ [50]. In contrast, in an Australian study, SMS text message reminders were used to improve hepatitis B vaccination among high-risk sexual health center attendees, and it was found that this intervention was not effective [51].

To the best of our knowledge, no study has used SMS text messaging technology to increase adherence to recommendations for CRC screening follow-up after a positive FOBT result. Therefore, we aimed to examine the effectiveness of sending SMS text messages to patients as an automated tool to increase adherence to colonoscopy follow-up and to examine the influence of physicians' attitude toward FOBT as a screening test for CRC and patient adherence to follow-up.

\section{Methods}

\section{Methodology}

This study was conducted between January 2016 and March 2017 in Meuhedet, 1 of 4 health care organizations in Israel. It insures and provides care for 1.2 million members. The current rate of colorectal screening among 180,000 members aged 50-75 years is $60 \%$, similar to the Israeli population. As per our data, in 2016, the rate of follow-up colonoscopy after a positive FOBT result in Meuhedet was $41 \%$. The FOBT test used in Meuhedet 
is OC-SENSOR Immunochemical Kit (Eiken Chemical Co, Ltd, Tokyo, Japan). The study was approved by the Meuhedet Institutional Review Board on March 23, 2016 (trial reference number: 01-023-03-016). The study was exempted from informed consent, and only agreement to receive SMS text messages was required. Figure 1 describes the study flow (Multimedia Appendix 1 presents the CONSORT checklist [52]).

\section{Study Population}

In 2016, 3397 patients aged 50-75 years had a positive FOBT result. Of them, 609 were randomly selected and, then, randomly allocated to the intervention or control group. The inclusion criteria included age 50-75 years and providing consent to receive SMS text messages from Meuhedet. By Israeli law, health messages via SMS text messages may only be sent to members who actively agree to receive them. The exclusion criteria were personal or family history of CRC, colonoscopy 10 years before the positive FOBT result, or diagnosis of any type of cancer during the study period.

\section{Physicians}

All primary care physicians whose patients (control and intervention groups) had completed an FOBT during 2016 and were employed by Meuhedet were included in this study. Physicians no longer working at Meuhedet were excluded from the study. All primary care physicians were notified about the study.

\section{Study Variables}

The independent variables were the intervention or control group and physician attitude to FOBT. In addition, we examined potential confounders such as gender, age, socioeconomic status (SES), ethnicity, and residential district. The dependent variable was adherence to colonoscopy within 120 days of a positive FOBT result. This information was obtained from the patients' electronic medical records (EMRs). Positive FOBT results were obtained from the Meuhedet Central Laboratory. Patients' demographics and clinical characteristics including gender, age, district, SES, and ethnicity were obtained from the EMRs. SMS text messages were sent to patients via InforUMobile software (Shamir Systems, 1974, Rishon LeZion) with a track whether the SMS text message was received or rejected.

Figure 1. Study selection and design. FOBT: fecal occult blood test; CRC: colorectal cancer; SMS: short message service.

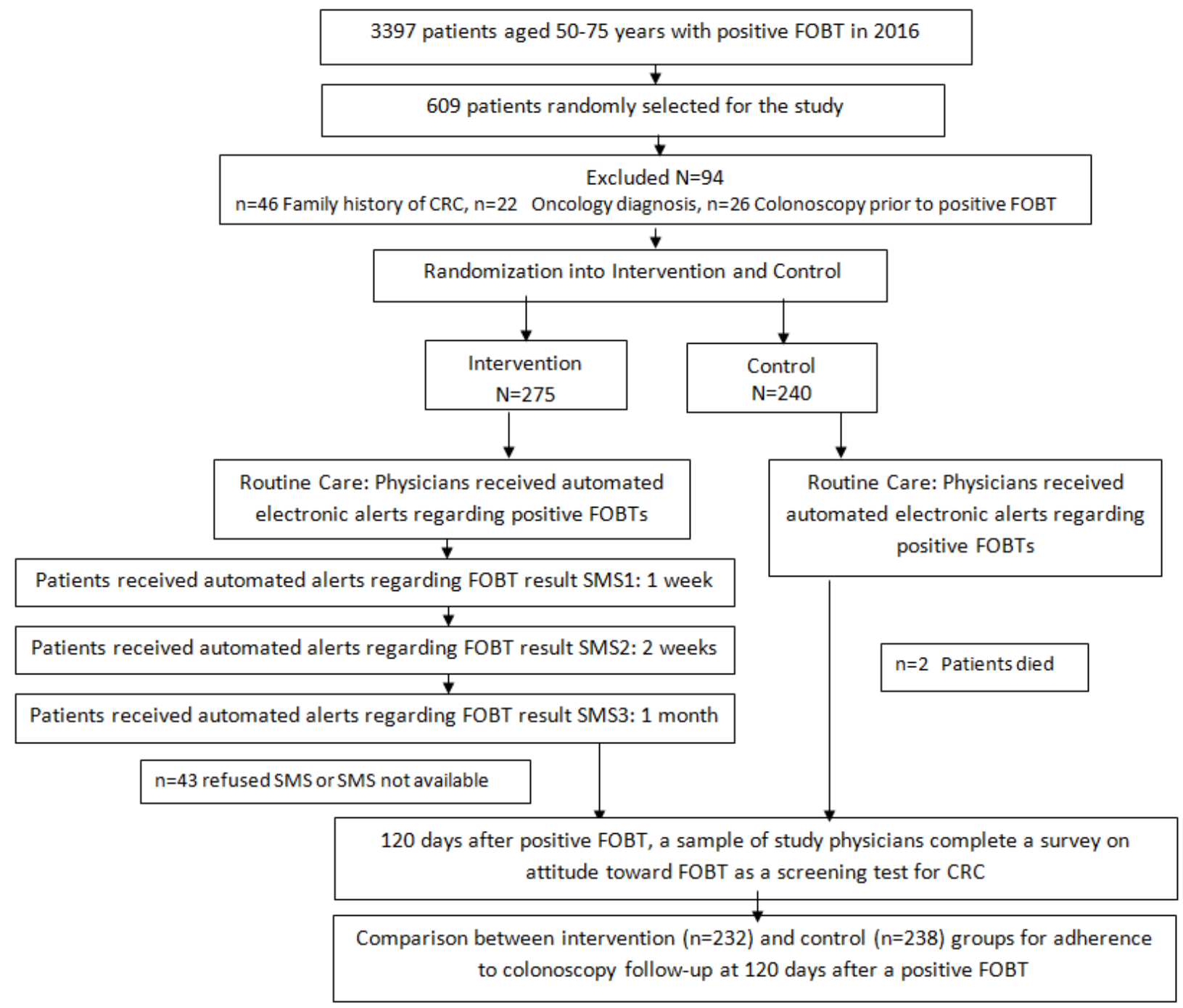




\section{Study Protocol}

Routine care for the control and intervention groups included an automated computer alert in a patient's EMR regarding the positive FOBT result, to his or her physician, with no indication of whether the patient had already visited the physician after the positive result. The automated alert was sent to physicians the moment the lab released the positive result. In addition, each patient in the intervention group received an automated SMS text message up to a week after the positive FOBT result. The text read: "Hello. There is a lab test result ready for you. Contact your physician for an explanation of the findings." Furthermore, 2 additional automated SMS text message reminders were sent to patients after 2 weeks and 1 month, reading, "Hello, This is a reminder. It is essential that you contact your physician if you have not already done so." As the SMS text messages were sent automatically to a randomly selected population, patients in the control group were not aware of the intervention. Physicians were blinded regarding which of their patients were in either group.

With no indication of whether a patient underwent colonoscopy, 120 days after the positive FOBT result, referring primary physicians (for both the control and intervention groups) answered a telephone survey regarding attitude toward FOBT as a screening test for CRC. We waited 120 days so as not to influence physicians' interactions with their patients. We focused on whether FOBT is a reliable screening test for CRC and whether physicians recommend a repeat FOBT after obtaining a positive FOBT result, instead of follow-up, such as colonoscopy (Figure 1). Physicians who stated that FOBT is not a reliable screening test for $\mathrm{CRC}$ or reported that they would advise the patient to repeat FOBT instead of sending him or her for colonoscopy were considered as having a negative attitude toward FOBT.

\section{Statistical Analysis}

Based on the statistical analysis of the Meuhedet patient database, we found that approximately $41 \%$ of patients with a positive FOBT result undergo colonoscopy within 120 days. To have an $80 \%$ chance of detecting a $20 \%$ increase in follow-up in the intervention group as significant (1-sided, 5\% level), a sample of 77 was required in each group. The study sample of 232 in each group provided a $95 \%$ ability to detect a $20 \%$ increase in adherence to colonoscopy within 120 days.

Randomization was stratified by district and SES derived from members' home address and based on the Israeli Census Bureau locality definitions [53]. SES levels ranged from 1 (low) to 20 (high). We compared demographic variables between the intervention and control groups using chi-square test for discrete variables. In addition, logistic regression was used to calculate odds ratios (ORs) and 95\% CIs for the rate of colonoscopy within 120 days of receiving a positive FOBT result, adjusting for the main potential and variables found to be significantly related to adherence in univariate analysis. Data were analyzed using IBM SPSS Statistics for Windows (IBM Corp, 2016, Version 24.0). $P<.05$ was considered significant for all analyses.

\section{Results}

\section{Study Population}

Of 609 patients randomly selected from the patient database, $94(15.4 \%)$ were excluded from the study sample: 46 (7.6\%) because of family history of CRC, $22(3.6 \%)$ because of an oncology diagnosis, and 26 (4.3\%) because they had undergone colonoscopy prior to the positive FOBT result. A total of 470 eligible patients were randomized: $232(49.4 \%)$ into the intervention group and $238(50.6 \%)$ into the control group. Of them, 2 patients in the control group died during the study period and $43(9.1 \%)$ in the intervention group refused to receive an SMS text message after their initial approval or were unable to receive SMS text message although they had agreed to receive it. Table 1 summarizes patient characteristics.

Just over half of the final participants were male (52.3\%, 246/470), and the mean age of participants was 62.0 (SD 6.6) years. Most participants were from the South district, and the fewest were from the North district. In both groups, most participants were in SES levels 9-13, but this value was missing for $11.9 \%$ (56/470) patients. Gender rates were similar between the intervention and control groups, and the groups were ethnically similar. Furthermore, geographic dispersion was similar.

Overall, 163 of 232 patients in the intervention group and 112 of 238 patients in the control group underwent colonoscopy within 120 days of the positive FOBT result (70.3\% vs $47.1 \%$; $P<.001)$. The unadjusted OR for completion of colonoscopy for the intervention versus control group was 2.17 (95\% CI $1.49-3.17 ; P<.001)$.

Table 2 presents the bivariate (unadjusted) association between patient characteristics and adherence to colonoscopy within 120 days of a positive FOBT result for the entire cohort $(\mathrm{N}=470)$. Adherence rates were similar across genders. Adherence rates were higher in the Central and North districts than in the South and Jerusalem districts. Adherence rates were higher among those aged 50-59 and 70-75 years and among those with higher SES levels. Adherence rates to colonoscopy within 120 days of a positive FOBT result were higher among patients who had physicians with a positive attitude toward FOBT than among those who had physicians with a negative attitude toward FOBT $(241 / 399,60.4 \%$ vs $24 / 53,45.3 \%$; $P=.04)$.

Logistic regression analysis was performed to determine whether colonoscopy rates differed between the groups after adjusting for potential confounders. The adjusted OR for adherence by the intervention group versus control group was 2.9 (95\% CI 1.92-4.48, $P=.001$; Table 3). We performed the analysis including the 43 patients who did not receive all 3 SMS text messages ("intention to treat") and found that adherence rates remained significantly higher both in the bivariate analysis $(63.5 \%$ vs $47.1 \%$ in the control group; OR $1.96,95 \%$ CI $1.37-2.79 ; P<.001)$ and in the multivariable model (OR 2.04, 95\% CI 1.387-2.993; $P<.001)$. 
Table 1. Patient characteristics.

\begin{tabular}{|c|c|c|c|}
\hline Characteristic & Control group (n=238), n (\%) & Intervention group $(\mathrm{n}=232), \mathrm{n}(\%)$ & Total $(\mathrm{N})$ \\
\hline \multicolumn{4}{|l|}{ Gender } \\
\hline Male & $125(52.5)$ & $121(52.2)$ & 246 \\
\hline Female & $113(47.5)$ & $111(47.8)$ & 224 \\
\hline \multicolumn{4}{|l|}{ Age (years) } \\
\hline $50-55$ & $41(17.2)$ & $45(19.5)$ & 86 \\
\hline $55-59$ & $40(16.8)$ & $39(16.8)$ & 79 \\
\hline $60-64$ & $63(26.5)$ & $53(22.8)$ & 116 \\
\hline $65-69$ & $66(27.7)$ & $66(28.4)$ & 132 \\
\hline $70-75$ & $28(11.8)$ & $29(12.5)$ & 57 \\
\hline \multicolumn{4}{|l|}{ Ethnicity } \\
\hline Jewish & $237(99.6)$ & $227(97.8)$ & 464 \\
\hline Other & $1(0.4)$ & $5(2.2)$ & 6 \\
\hline \multicolumn{4}{|c|}{ National district } \\
\hline South & $83(34.9)$ & $99(42.7)$ & 182 \\
\hline Jerusalem & $60(25.2)$ & $49(21.1)$ & 109 \\
\hline Center & $50(21.0)$ & $46(19.8)$ & 96 \\
\hline North & $45(18.9)$ & $38(16.4)$ & 83 \\
\hline \multicolumn{4}{|c|}{ Socioeconomic status level $^{\mathrm{a}}$} \\
\hline $1-8$ & $13(6.3)$ & $20(9.6)$ & 33 \\
\hline $9-13$ & $116(56.6)$ & $122(58.4)$ & 238 \\
\hline $14-20$ & $76(37.1)$ & $67(32.0)$ & 143 \\
\hline
\end{tabular}

${ }_{n}=414$; data missing for 56 patients. 
Table 2. Adherence within 120 days after a positive fecal occult blood test result for individual variables.

\begin{tabular}{|c|c|c|c|}
\hline Variable & $\begin{array}{l}\text { Did not adhere to colonoscopy } \\
(\mathrm{n}=195), \mathrm{n}(\%)\end{array}$ & $\begin{array}{l}\text { Adhered to colonoscopy }{ }^{b}(n=275) \\
n(\%)\end{array}$ & $P$ value \\
\hline Intervention versus control & & & $<.001$ \\
\hline Intervention & $69(29.7)$ & $163(70.3)$ & \\
\hline Control & $126(52.9)$ & $112(47.1)$ & \\
\hline Gender & & & .26 \\
\hline Male & $96(39)$ & $150(61)$ & \\
\hline Female & $99(44.2)$ & $125(55.8)$ & \\
\hline Age (years) & $195(41.5)$ & $275(58.5)$ & .91 \\
\hline $50-54$ & $35(40.7)$ & $51(59.3)$ & \\
\hline $55-59$ & $32(40.5)$ & $47(59.5)$ & \\
\hline $60-64$ & $49(42.2)$ & $67(57.8)$ & \\
\hline $65-69$ & $56(42.4)$ & $76(57.6)$ & \\
\hline $70-75$ & $23(40.4)$ & $34(59.6)$ & \\
\hline District & $195(41.5)$ & $275(58.5)$ & .36 \\
\hline South & $79(43.4)$ & $103(56.6)$ & \\
\hline Jerusalem & $51(46.8)$ & $58(53.2)$ & \\
\hline Center & $33(34.4)$ & $63(65.6)$ & \\
\hline North & $32(38.6)$ & $51(61.4)$ & \\
\hline Socioeconomic status level $^{c}$ & & & .10 \\
\hline $1-8$ & $18(54.5)$ & $15(45.5)$ & \\
\hline $9-13$ & $100(42.0)$ & $138(58.0)$ & \\
\hline $14-20$ & $58(40.6)$ & $85(59.4)$ & \\
\hline Physician attitude $^{d}$ & & & .04 \\
\hline Positive attitude & $158(39.6)$ & $241(60.4)$ & \\
\hline Negative attitude & $29(54.7)$ & $24(45.3)$ & \\
\hline
\end{tabular}

${ }^{\mathrm{a}}$ Of all, $41.5 \%$ patients did not adhere to colonoscopy.

${ }^{\mathrm{b}} \mathrm{Of}$ all, 58.5\% patients adhered to colonoscopy.

${ }^{\mathrm{c}}$ Data missing for 56 patients.

${ }^{\mathrm{d}}$ Data missing for 18 patients.

\section{Physicians}

Among 282 primary physicians who referred participants to FOBT, 267 (94.7\%) were interviewed, 4 (1.4\%) refused, 9 $(3.2 \%)$ could not be contacted, and $2(0.9 \%)$ had left the organization. Most $(83.5 \%, 223 / 267)$ physicians had a positive attitude toward FOBT as a tool for early detection of CRC. The adjusted OR for patients who had a physician with a positive attitude toward FOBT versus a negative attitude was $2.7(95 \%$ CI 1.38-5.33; $P=.004$; Table 3). As some patients were referred for FOBT by the same primary care physician, we performed a binomial mixed model analysis to assess the impact of physician-level clustering. No difference was found, and the OR of the intervention group remained the same compared with that of the control group (2.9).

We conducted the intention-to-treat analysis including the 43 patients who did not receive the SMS text message and found that adherence rates remained significantly higher both in the bivariate $(63.5 \%$ vs $47.1 \%$ in the control group; OR $1.96,95 \%$ CI 1.37-2.79; $P<.001$ ) and the multivariable (OR 2.04, 95\% CI $1.387-2.993 ; P<.001)$ analyses. As we only contacted physicians of patients who completed the study, we were unable to run the full multivariable model (including physician attitude). 
Table 3. Multivariable analysis of colonoscopy rates.

\begin{tabular}{|c|c|c|c|}
\hline Variable & Odds ratio & $95 \% \mathrm{CI}$ & $P$ value \\
\hline Intervention vs Control & 2.93 & $1.92-4.48$ & $<.001$ \\
\hline Age (continuous) & 1.01 & $0.98-1.04$ & .48 \\
\hline Female versus Male & 0.81 & $0.53-1.22$ & .31 \\
\hline Socioeconomic status (continuous, $1-20$ ) & 0.99 & $0.92-1.07$ & .91 \\
\hline \multicolumn{4}{|l|}{ South district } \\
\hline Jerusalem district & 1.26 & $0.72-2.20$ & .41 \\
\hline Center district & 1.92 & $1.04-3.55$ & .04 \\
\hline North district & 1.59 & $0.87-2.91$ & .13 \\
\hline FOBT $^{\mathrm{a}}$ attitude: Positive versus Negative & 2.72 & $1.38-5.33$ & .004 \\
\hline Constant & 0.09 & $-\mathrm{b}$ & .15 \\
\hline
\end{tabular}

${ }^{\mathrm{a}}$ FOBT: fecal occult blood test.

${ }^{\mathrm{b}}$ Not applicable.

\section{Discussion}

The effectiveness of mass cancer screening programs can be compromised by lack of follow-up of abnormal findings. Incomplete FOBT follow-up with colonoscopy is a significant problem that has been studied extensively. This study shows that sending SMS text message reminders to patients following a positive FOBT result is an effective way to increase adherence rates to follow-up colonoscopy. In this study, there was a relative increase of $49.2 \%$ in adherence in the intervention group using a simple, inexpensive means of communication. This surprisingly large increase in adherence could be a result of a combination of simplicity, repetition, and timeliness. Reminders were simply worded, with a clear message, sent immediately after results were obtained, and then repeated twice over the next month. Another potential advantage is that unlike telephone calls, which require active responses, the messages are "pushed." Probably, patients who responded to the message were those who were more likely to complete the follow-up but required a "nudge." Another possibility is that the message created cognitive dissonance in some patients who chose to ignore the results until they received the reminder. Future research should focus on how different contact methods are effective for different types of patients.

In this study, age, gender, SES, and geographic location were not significantly associated with adherence to follow-up of positive FOBT results either in the bivariate or multivariable analysis. Increasing age was previously associated with lack of follow-up in some studies [39], but not in others [21]. Similar to our findings, several studies did not find strong associations between gender and complete diagnostic follow-up [21,29,54]. However, others suggested that women are less likely than men to undergo follow-up testing [16,25,55]. Although the association between SES and follow-up was not significant, there appears to be a trend toward increasing follow-up rates at higher SES. This needs to be investigated further.

The physician plays an important role in a patient's decision regarding follow-up tests. Trust in the physician and good communication between the patient and physician will positively influence the adherence rates of patients after a positive FOBT result. In this study, 95.1\% (254/267) of physicians declared that FOBT is a reliable screening test for CRC and that they would not advise their patients to undergo FOBT again to ensure that the positive result is reliable. The physician's attitude toward FOBT as a screening test significantly influences the patient's adherence to colonoscopy.

A new finding of this study is that physicians' attitude toward FOBT has a major influence on the rates of colonoscopy after a positive FOBT result. This finding may explain why intervention studies that provide physicians with knowledge and feedback have been effective. For example, Myers et al [56] showed that one-on-one physician training, audit, and feedback (physicians received lists of their patients with incomplete diagnostic evaluations) resulted in improved completion of diagnostic testing. Singh et al [57] assessed a clinic-based quality improvement activity that included provider education, a positive FOBT registry, and feedback; they found that it significantly decreased the time to colonoscopy referral and completion and increased colonoscopy completion by $18.7 \%$. In spite of the fact that FOBT has been a standard practice for early detection of $\mathrm{CRC},>10 \%$ of physicians in our study expressed mistrust in this method; this is possibly an underestimate, as some physicians may hesitate to express this view openly, which is contrary to organizational guidelines. It is, therefore, essential to educate physicians regarding the reliability and effectiveness of FOBT as a screening tool for CRC.

Owing to recent developments that have made digital communication within the health care sector readily available and inexpensive, SMS text message reminders could potentially be implemented in other areas. The finding of a large increase in follow-up after a positive FOBT result illustrates the need to further investigate different aspects of SMS text message usage, such as patients' age, gender, the type of action they aim to increase, and the wording of the message. Changing technology and patient preferences with regard to contact communication 
should be considered when determining future interventions to improve usage and effectiveness.

A limitation of this study is that only patients who agreed to receive SMS text messages were included, which created a biased population in terms of age, cultural beliefs, and SES. An additional limitation is that SES was measured using zip code rather than a direct measure, and the SES of 56 participants was missing, although this is the standard method for measuring SES in Israel.

This study was conducted in 1 of the 4 health care provider organizations in Israel. Selection of providers was voluntary, and the member distribution in terms of age, gender, and SES was similar to that of the Israeli population. In addition, the Israeli population is very ethnically diverse and includes immigrants from many countries. Our findings are potentially generalizable to other populations.
In conclusion, this study is the first to directly evaluate SMS text message reminders for improving colonoscopy follow-up among Israeli CRC screening program participants following a positive FOBT result. We have shown that a simple, inexpensive intervention for patients improves colonoscopy follow-up after a positive FOBT result. It is important to maximize the potential of these findings by increasing the acceptance of SMS text messages within the population and to examine their use in other screening programs. In addition, it is important to examine, in future studies, the reasons because of which patients refuse to receive SMS text messages. The physician's attitude toward FOBT as a screening test significantly influences patient adherence to colonoscopy. Therefore, further work needs to be done among physicians to increase adherence.

\title{
Acknowledgments
}

We thank Professor Haim Reuveni for his help throughout the research process. This study was written as a PhD thesis at Bar Ilan University, Public Health and Health Systems Management Program, Department of Management, under the direction of Racheli Magnezi, PhD, MBA, MHA, and Professor Haim Reuveni. The study was approved on February 23, 2016.

\section{Conflicts of Interest}

None declared.

\author{
Multimedia Appendix 1 \\ CONSORT - EHEALTH checklist (V 1.6.1). \\ [PDF File (Adobe PDF File), 134KB-Multimedia Appendix 1]
}

\section{References}

1. Ministry of Health, State of Israel. 2018. Colorectal Cancer in Israel: Updated March 2016 URL: https://www.health.gov.il/ PublicationsFiles/ICR 04032016.pdf [accessed 2018-05-18] [WebCite Cache ID 74W4CDJtR]

2. Global Cancer Observatory. 2018. Colorectal cancer URL: http://gco.iarc.fr/today/data/factsheets/cancers/ 108 9-Colorectum-fact-sheet.pdf [accessed 2018-05-18] [WebCite Cache ID 74W4xP0Xe]

3. Ministry of Health, State of Israel. 2018. Prevention and early detection of malignant diseases URL: https://www.health.gov.il/ hozer/mk08 2011.pdf [accessed 2018-05-18] [WebCite Cache ID 74W57kxxe]

4. Meester RGS, Doubeni CA, Lansdorp-Vogelaar I, Goede SL, Levin TR, Quinn VP, et al. Colorectal cancer deaths attributable to nonuse of screening in the United States. Ann Epidemiol 2015 Mar;25(3):208-213.e1 [FREE Full text] [doi: 10.1016/j.annepidem.2014.11.011] [Medline: 25721748]

5. Chubak J, Garcia MP, Burnett-Hartman AN, Zheng Y, Corley DA, Halm EA, PROSPR consortium. Time to Colonoscopy after Positive Fecal Blood Test in Four U.S. Health Care Systems. Cancer Epidemiol Biomarkers Prev 2016 Feb;25(2):344-350 [FREE Full text] [doi: 10.1158/1055-9965.EPI-15-0470] [Medline: 26843520]

6. Etzioni DA, Yano EM, Rubenstein LV, Lee ML, Ko CY, Brook RH, et al. Measuring the quality of colorectal cancer screening: the importance of follow-up. Dis Colon Rectum 2006 Jul;49(7):1002-1010. [doi: 10.1007/s10350-006-0533-2] [Medline: 16673056$]$

7. Meester RGS, Zauber AG, Doubeni CA, Jensen CD, Quinn VP, Helfand M, et al. Consequences of Increasing Time to Colonoscopy Examination After Positive Result From Fecal Colorectal Cancer Screening Test. Clin Gastroenterol Hepatol 2016 Dec;14(10):1445-1451.e8 [FREE Full text] [doi: 10.1016/j.cgh.2016.05.017] [Medline: 27211498]

8. Liss DT, Brown T, Lee JY, Altergott M, Buchanan DR, Newland A, et al. Diagnostic colonoscopy following a positive fecal occult blood test in community health center patients. Cancer Causes Control 2016 Dec;27(7):881-887. [doi: 10.1007/s10552-016-0763-0] [Medline: 27228991]

9. Oluloro A, Petrik AF, Turner A, Kapka T, Rivelli J, Carney PA, et al. Timeliness of Colonoscopy After Abnormal Fecal Test Results in a Safety Net Practice. J Community Health 2016 Dec;41(4):864-870 [FREE Full text] [doi: 10.1007/s10900-016-0165-y] [Medline: 26874943] 
10. Paterson WG, Depew WT, Paré P, Petrunia D, Switzer C, Veldhuyzen van Zanten SJ, Canadian Association of Gastroenterology Wait Time Consensus Group. Canadian consensus on medically acceptable wait times for digestive health care. Can J Gastroenterol 2006 Jun;20(6):411-423 [FREE Full text] [Medline: 16779459]

11. Viiala CH, Tang KW, Lawrance IC, Murray K, Olynyk JK. Waiting times for colonoscopy and colorectal cancer diagnosis. Med J Aust 2007 Mar 19;186(6):282-285. [Medline: 17371207]

12. Lee HY, Choi KS, Jun JK, Hahm MI, Park EC. Time to follow up after an abnormal finding in organized gastric cancer screening in Korea. BMC Cancer 2012 Sep 10;12:400 [FREE Full text] [doi: 10.1186/1471-2407-12-400] [Medline: 22963347]

13. Steele RJC, McClements PL, Libby G, Black R, Morton C, Birrell J, et al. Results from the first three rounds of the Scottish demonstration pilot of FOBT screening for colorectal cancer. Gut 2009 Apr;58(4):530-535. [doi: 10.1136/gut.2008.162883] [Medline: 19036949 ]

14. Ministry of Health, State of Israel. Occult Blood Test-CRC Screening Program in Israel URL: https://www.health.gov.il/ hozer/mr12_2014.pdf [accessed 2018-05-18] [WebCite Cache ID 74W5Doh5o]

15. Thamarasseril S, Bhuket T, Chan C, Liu B, Wong RJ. The Need for an Integrated Patient Navigation Pathway to Improve Access to Colonoscopy After Positive Fecal Immunochemical Testing: A Safety-Net Hospital Experience. J Community Health 2017 Jun;42(3):551-557. [doi: 10.1007/s10900-016-0287-2] [Medline: 27796633]

16. Singh H, Kadiyala H, Bhagwath G, Shethia A, El-Serag H, Walder A, et al. Using a multifaceted approach to improve the follow-up of positive fecal occult blood test results. Am J Gastroenterol 2009 Apr;104(4):942-952 [FREE Full text] [doi: 10.1038/ajg.2009.55] [Medline: 19293786]

17. The Israel National Institute for Health Policy Research. 2015. National Program for Quality Indicators in Community Health care 2013-2015 URL: http://www.israelhpr.org.il/1043/470.htm [accessed 2018-12-11] [WebCite Cache ID 74aPhvCi4]

18. Fiscella K, Humiston S, Hendren S, Winters P, Jean-Pierre P, Idris A, et al. Eliminating disparities in cancer screening and follow-up of abnormal results: what will it take? J Health Care Poor Underserved 2011 Feb;22(1):83-100 [FREE Full text] [doi: 10.1353/hpu.2011.0023] [Medline: 21317508]

19. Emery J, Trevena L, Mazza D, Fallon-Ferguson J, Shaw K, Williams B, et al. Sax Institute. 2012 Dec. The role of primary and communitybased healthcare professionals in early detection and follow-up in cancer care: a rapid review of best practice models URL: https://www.saxinstitute.org.au/wp-content/uploads/REPORT_Role-of-PHC-cancer-early-detection-2smallpdf. com .pdf [accessed 2018-05-18] [WebCite Cache ID 6zVCoTkp2]

20. Martin J, Halm EA, Tiro JA, Merchant Z, Balasubramanian BA, McCallister K, et al. Reasons for Lack of Diagnostic Colonoscopy After Positive Result on Fecal Immunochemical Test in a Safety-Net Health System. Am J Med 2017 Jan;130(1):93.e1-93.e7 [FREE Full text] [doi: 10.1016/j.amjmed.2016.07.028] [Medline: 27591183]

21. Ferrat E, Le Breton J, Veerabudun K, Bercier S, Brixi Z, Khoshnood B, et al. Colorectal cancer screening: factors associated with colonoscopy after a positive faecal occult blood test. Br J Cancer 2013 Sep 17;109(6):1437-1444 [FREE Full text] [doi: 10.1038/bjc.2013.476] [Medline: 23989948]

22. Plumb AA, Ghanouni A, Rainbow S, Djedovic N, Marshall S, Stein J, et al. Patient factors associated with non-attendance at colonoscopy after a positive screening faecal occult blood test. J Med Screen 2017 Dec;24(1):12-19. [doi: 10.1177/0969141316645629] [Medline: 27216771]

23. Laing SS, Bogart A, Chubak J, Fuller S, Green BB. Psychological distress after a positive fecal occult blood test result among members of an integrated healthcare delivery system. Cancer Epidemiol Biomarkers Prev 2014 Jan;23(1):154-159 [FREE Full text] [doi: 10.1158/1055-9965.EPI-13-0722] [Medline: 24220914]

24. Humphrey LL, Shannon J, Partin MR, O'Malley J, Chen Z, Helfand M. Improving the follow-up of positive hemoccult screening tests: an electronic intervention. J Gen Intern Med 2011 Jul;26(7):691-697 [FREE Full text] [doi: 10.1007/s11606-011-1639-3] [Medline: 21327529]

25. Miglioretti DL, Rutter CM, Bradford SC, Zauber AG, Kessler LG, Feuer EJ, et al. Improvement in the diagnostic evaluation of a positive fecal occult blood test in an integrated health care organization. Med Care 2008 Sep;46(9 Suppl 1):S91-S96 [FREE Full text] [doi: 10.1097/MLR.0b013e31817946c8] [Medline: 18725839]

26. Partin MR, Burgess DJ, Burgess JF, Gravely A, Haggstrom D, Lillie SE, et al. Organizational predictors of colonoscopy follow-up for positive fecal occult blood test results: an observational study. Cancer Epidemiol Biomarkers Prev 2015 Feb;24(2):422-434 [FREE Full text] [doi: 10.1158/1055-9965.EPI-14-1170] [Medline: 25471345]

27. Yabroff KR, Washington KS, Leader A, Neilson E, Mandelblatt J. Is the promise of cancer-screening programs being compromised? Quality of follow-up care after abnormal screening results. Med Care Res Rev 2003 Sep;60(3):294-331. [doi: 10.1177/1077558703254698] [Medline: 12971231]

28. Callen JL, Westbrook JI, Georgiou A, Li J. Failure to follow-up test results for ambulatory patients: a systematic review. J Gen Intern Med 2012 Oct;27(10):1334-1348 [FREE Full text] [doi: 10.1007/s11606-011-1949-5] [Medline: 22183961]

29. Shields HM, Weiner MS, Henry DR, Lloyd JA, Ransil BJ, Lamphier DA, et al. Factors that influence the decision to do an adequate evaluation of a patient with a positive stool for occult blood. Am J Gastroenterol 2001 Jan;96(1):196-203. [doi: 10.1111/j.1572-0241.2001.03475.x] [Medline: 11197252] 
30. Taplin SH, Yabroff KR, Zapka J. A multilevel research perspective on cancer care delivery: the example of follow-up to an abnormal mammogram. Cancer Epidemiol Biomarkers Prev 2012 Oct;21(10):1709-1715 [FREE Full text] [doi: 10.1158/1055-9965.EPI-12-0265] [Medline: 22911332]

31. Stock D, Rabeneck L, Baxter NN, Paszat LF, Sutradhar R, Yun L, et al. Mailed participant reminders are associated with improved colonoscopy uptake after a positive FOBT result in Ontario's ColonCancerCheck program. Implement Sci 2015 Mar 13;10:35 [FREE Full text] [doi: 10.1186/s13012-015-0226-0] [Medline: 25885531]

32. Chen ZJ, Kammer D, Bond JH, Ho SB. Evaluating follow-up of positive fecal occult blood test results: lessons learned. J Healthc Qual 2007;29(5):16-20, 34. [Medline: 17892078]

33. Zapka J, Taplin SH, Price RA, Cranos C, Yabroff R. Factors in quality care--the case of follow-up to abnormal cancer screening tests--problems in the steps and interfaces of care. J Natl Cancer Inst Monogr 2010;2010(40):58-71 [FREE Full text] [doi: 10.1093/jncimonographs/lgq009] [Medline: 20386054]

34. Bastani R, Yabroff KR, Myers RE, Glenn B. Interventions to improve follow-up of abnormal findings in cancer screening. Cancer 2004 Sep 01;101(5 Suppl):1188-1200 [FREE Full text] [doi: 10.1002/cncr.20506] [Medline: 15316914]

35. Green BB, Wang CY, Horner K, Catz S, Meenan RT, Vernon SW, et al. Systems of support to increase colorectal cancer screening and follow-up rates (SOS): design, challenges, and baseline characteristics of trial participants. Contemp Clin Trials 2010 Nov;31(6):589-603 [FREE Full text] [doi: 10.1016/j.cct.2010.07.012] [Medline: 20674774]

36. Lee J, Fulp W, Wells KJ, Meade CD, Calcano E, Roetzheim R. Effect of patient navigation on time to diagnostic resolution among patients with colorectal cancer-related abnormalities. J Cancer Educ 2014 Mar;29(1):144-150 [FREE Full text] [doi: 10.1007/s13187-013-0561-2] [Medline: 24113902]

37. Green BB, Anderson ML, Wang C, Vernon SW, Chubak J, Meenan RT, et al. Results of nurse navigator follow-up after positive colorectal cancer screening test: a randomized trial. J Am Board Fam Med 2014;27(6):789-795 [FREE Full text] [doi: 10.3122/jabfm.2014.06.140125] [Medline: 25381076]

38. Zheng Y, Saito T, Takahashi M, Ishibashi T, Kai I. Factors associated with intentions to adhere to colorectal cancer screening follow-up exams. BMC Public Health 2006 Nov 06;6:272 [ [FREE Full text] [doi: 10.1186/1471-2458-6-272] [Medline: 17083746]

39. Morris S, Baio G, Kendall E, von Wagner C, Wardle J, Atkin W, et al. Socioeconomic variation in uptake of colonoscopy following a positive faecal occult blood test result: a retrospective analysis of the NHS Bowel Cancer Screening Programme. Br J Cancer 2012 Aug 21;107(5):765-771 [FREE Full text] [doi: 10.1038/bjc.2012.303] [Medline: 22864455]

40. Zorzi M, Giorgi Rossi P, Cogo C, Falcini F, Giorgi D, Grazzini G, PARC Working Group. A comparison of different strategies used to invite subjects with a positive faecal occult blood test to a colonoscopy assessment. A randomised controlled trial in population-based screening programmes. Prev Med 2014 Aug;65:70-76. [doi: 10.1016/j.ypmed.2014.04.022] [Medline: 24811759]

41. Chiu H, Hung H, Lin H, Chen S. Effects of a health education and telephone counseling program on patients with a positive fecal occult blood test result for colorectal cancer screening: A randomized controlled trial. Psychooncology 2017 Oct;26(10):1498-1504. [doi: 10.1002/pon.4319] [Medline: 27859897]

42. Gupta S, Brenner AT, Ratanawongsa N, Inadomi JM. Patient trust in physician influences colorectal cancer screening in low-income patients. Am J Prev Med 2014 Oct;47(4):417-423 [FREE Full text] [doi: 10.1016/j.amepre.2014.04.020] [Medline: 25084682]

43. Hudson SV, Ferrante JM, Ohman-Strickland P, Hahn KA, Shaw EK, Hemler J, et al. Physician recommendation and patient adherence for colorectal cancer screening. J Am Board Fam Med 2012;25(6):782-791 [FREE Full text] [doi:

10.3122/jabfm.2012.06.110254] [Medline: 23136316]

44. Park J, Kim T, Lee N, Kim H, Seo EH, Heo N, et al. The Effectiveness of Short Message Service to Assure the Preparation-to-Colonoscopy Interval before Bowel Preparation for Colonoscopy. Gastroenterol Res Pract 2015;2015:628049 [FREE Full text] [doi: 10.1155/2015/628049] [Medline: 25792978]

45. Ghadieh AS, Hamadeh GN, Mahmassani DM, Lakkis NA. The effect of various types of patients' reminders on the uptake of pneumococcal vaccine in adults: A randomized controlled trial. Vaccine 2015 Oct 26;33(43):5868-5872. [doi: 10.1016/j.vaccine.2015.07.050] [Medline: 26232345]

46. Nuti L, Turkcan A, Lawley MA, Zhang L, Sands L, McComb S. The impact of interventions on appointment and clinical outcomes for individuals with diabetes: a systematic review. BMC Health Serv Res 2015 Sep 02;15:355 [FREE Full text] [doi: 10.1186/s12913-015-0938-5] [Medline: 26330299]

47. Ershad Sarabi R, Sadoughi F, Jamshidi Orak R, Bahaadinbeigy K. The Effectiveness of Mobile Phone Text Messaging in Improving Medication Adherence for Patients with Chronic Diseases: A Systematic Review. Iran Red Crescent Med J 2016 May;18(5):e25183 [FREE Full text] [doi: 10.5812/ircmj.25183] [Medline: 27437126]

48. Johnston N, Weinman J, Ashworth L, Smethurst P, El Khoury J, Moloney C. Systematic reviews: causes of non-adherence to P2Y12 inhibitors in acute coronary syndromes and response to intervention. Open Heart 2016;3(2):e000479 [FREE Full text] [doi: 10.1136/openhrt-2016-000479] [Medline: 27843565]

49. Akhu-Zaheya LM, Shiyab WY. The effect of short message system (SMS) reminder on adherence to a healthy diet, medication, and cessation of smoking among adult patients with cardiovascular diseases. Int J Med Inform 2017 Dec;98:65-75. [doi: 10.1016/j.ijmedinf.2016.12.003] [Medline: 28034414] 
50. Önür ST, Uysal MA, İliaz S, Yurt S, Bahadır A, Hattatoğlu DG, et al. Does Short Message Service Increase Adherence to Smoking Cessation Clinic Appointments and Quitting Smoking? Balkan Med J 2016 Sep;33(5):525-531 [FREE Full text] [doi: 10.5152/balkanmedj.2016.151610] [Medline: 27761280]

51. McIver R, Dyda A, McNulty AM, Knight V, Wand HC, Guy RJ. Text message reminders do not improve hepatitis B vaccination rates in an Australian sexual health setting. J Am Med Inform Assoc 2016 Apr;23(e1):e88-e92 [FREE Full text] [doi: 10.1093/jamia/ocv145] [Medline: 26499103]

52. Eysenbach G, CONSORT-EHEALTH Group. CONSORT-EHEALTH: improving and standardizing evaluation reports of Web-based and mobile health interventions. J Med Internet Res 2011 Dec 31;13(4):e126 [FREE Full text] [doi: 10.2196/jmir.1923] [Medline: 22209829]

53. State of Israel: Central Bureau of Statistics. 2018. URL: http://www.cbs.gov.il/reader/ [accessed 2018-05-18] [WebCite Cache ID 74W5JQkF8]

54. Gellad ZF, Almirall D, Provenzale D, Fisher DA. Time from positive screening fecal occult blood test to colonoscopy and risk of neoplasia. Dig Dis Sci 2009 Nov;54(11):2497-2502 [FREE Full text] [doi: 10.1007/s10620-008-0653-8] [Medline: 19093199]

55. Turner B, Myers RE, Hyslop T, Hauck WW, Weinberg D, Brigham T, et al. Physician and patient factors associated with ordering a colon evaluation after a positive fecal occult blood test. J Gen Intern Med 2003 May;18(5):357-363 [FREE Full $\underline{\text { text] }}$ [Medline: 12795734]

56. Myers RE, Turner B, Weinberg D, Hyslop T, Hauck WW, Brigham T, et al. Impact of a physician-oriented intervention on follow-up in colorectal cancer screening. Prev Med 2004 Apr;38(4):375-381. [doi: 10.1016/j.ypmed.2003.11.010] [Medline: $\underline{15020170]}$

57. Singh H, Petersen LA, Daci K, Collins C, Khan M, El-Serag HB. Reducing referral delays in colorectal cancer diagnosis: is it about how you ask? Qual Saf Health Care 2010 Oct;19(5):e27 [FREE Full text] [doi: 10.1136/qshc.2009.033712] [Medline: 20584706]

\section{Abbreviations \\ CRC: colorectal cancer \\ EMR: electronic medical record \\ FOBT: fecal occult blood test \\ OR: odds ratio \\ SES: socioeconomic status \\ SMS: short message service}

Edited by G Eysenbach; submitted 23.05.18; peer-reviewed by C Rutter, D Liss, J Chubak, M Anderson; comments to author 07.08.18;
revised version received 25.08.18; accepted 26.10.18; published 05.02.19
Please cite as:
Azulay R, Valinsky L, Hershkowitz F, Magnezi R
Repeated Automated Mobile Text Messaging Reminders for Follow-Up of Positive Fecal Occult Blood Tests: Randomized Controlled
Trial
JMIR Mhealth Uhealth 2019;7(2):e11114
URL: $\underline{\text { http://mhealth.jmir.org/2019/2/e11114/ }}$
doi: $10.2196 / 11114$
PMID: $\underline{30720439}$

CRevital Azulay, Liora Valinsky, Fabienne Hershkowitz, Racheli Magnezi. Originally published in JMIR Mhealth and Uhealth (http://mhealth.jmir.org), 05.02.2019. This is an open-access article distributed under the terms of the Creative Commons Attribution License (https://creativecommons.org/licenses/by/4.0/), which permits unrestricted use, distribution, and reproduction in any medium, provided the original work, first published in JMIR mhealth and uhealth, is properly cited. The complete bibliographic information, a link to the original publication on http://mhealth.jmir.org/, as well as this copyright and license information must be included. 